\title{
An Experimental Study on the Monitoring of Wire Breaks in Bridge Cables
}

\author{
Qiang $\mathrm{Liu}^{1 \dagger}$, Guangming $\mathrm{Li}^{1{ }^{1 *}}$, Qingchao Gong ${ }^{1}$, Ruijuan Jiang ${ }^{2 *}$ and Yiyan $\mathrm{Chen}^{2}$ \\ ${ }^{1}$ School of Mechanical, Electrical and Information Engineering, Shandong \\ University, Weihai, PA 264209, China \\ ${ }^{2}$ Shenzhen Municipal Design \& Research Institute Co., Ltd., Shenzhen, PA \\ 518029, China \\ liuqiangwh@126.com,gmli@sdu.edu.com,gongqchao@163.com
}

\begin{abstract}
Bridge cables are important safety components of long-span cable bridges. What's more, how to exactly figure out broken wires in cables really matters in bridge structural health monitoring. This paper, which simulates wire breaks by releasing the steel strands one by one on the funicular machine, collates and analyzes the broken wires' experimental data. In this process, we used fiber Bragg grating sensor (FBGS) and the metal strain gauges for data acquisition, as well as MATLAB for the polynomial curve fitting of the experimental data. The results show that the shape of the broken wires' calibration curves is basically the same as the strain calibration curves. Based on calibration curves, engineers can determine the necessity of cable replacement by estimating the quantity of broken wires. This paper provides an effective technologic solution to detect broken wires in bridge cables accurately.
\end{abstract}

Keywords: bridge cable; broken wires; calibration curve; Fiber Bragg grating sensors (FBGS); metal strain gauge

\section{Introduction}

At present, structural health monitoring (SHM) has been extensively implemented on existing or newly built bridges in Europe, USA, Canada, Japan, Korea, China, and many other countries $[1,2]$.Bridge cables are the most important force suffering part of cable bridges such as cable-stayed bridges, hanging bridges, arch bridges, and suspension bridges. Bridge cables readily suffer from fatigue damage, corrosion damage, and their coupled effects [3]. Its reliability has great influence on the overall performance of the bridges. Therefore cables need to be constantly monitored for the reliable operation of bridges. Most large and medium-sized bridges have established the SHM system based on the method of monitoring the cables $[4,5]$. However, the following problems still exist in these methods currently: firstly, while a single cable appear broken wires, the inner stress of this cable will redistribute, and then the tension of other steel wires or strands will increase. Due to the broken wires, the hanger's vertical stiffness will decrease, thereby the whole bridge system appear to stress redistribution. So the force change of the whole cable is not significant. Secondly, if there is a large amount of broken wires, only the significant change of cable force can be monitored which take place on one certain cable or a few cables. But it is difficult to judge which cable appears broken wires, the exact amount of broken wires is also hard to calculate [6-9].

Therefore, how to assess the broken wires' condition of the cable bridges in a real time is the challenge this paper aims to solve. Since both the cable force status and the change of internal stress distribution can most directly reflect the health status of the bridge structure [10-13], this paper makes a simulation of cable broken wires, establishes the 
one-to-one corresponding relationship between the cable's strain value and the amount of broken wires, thus getting the calibration curve about strain and the amount of broken wires. Research work of this paper, on the one hand, solves the technical problem that existing detection methods are difficult to detect the damage of the cable accurately, making it possible to get early warnings when cables reach to the critical damage condition ,thus avoiding major accidents such as bridge collapse, this research has important significance in guaranteeing the safety of bridge cables; on the other hand, by using the technique mentioned in this paper we can figure out which cable needs to be replaced. It provides the basis for the continuous usage of bridge cables with complete structure, avoids the huge waste caused by replacing cables blindly [14]. This research has obvious benefits both to the society and the economy.

\section{The Scheme of the Experimental System}

In order to get calibration curve of the cable broken wires, this experiment simulates cable broken wires by releasing the steel strands one by one on the funicular machine. Specific operation method is as follows: Before the tensioning, take the clamping piece down from the steel strand which needs to achieve broken wires, locking this steel strand up by oil jack. Then tension the cable to the predetermined load. When the tensile force of cable is not changed any more, suddenly release the load of oil jack, to achieve the purpose of simulating cable broken wires. In recent years, FBGS show advantages over conventional sensing technology in accuracy, durability and operating distance and has been applied to long-term monitoring of Civil Engineering [15]. Considering technical application practice, the experiment use FBGSs and the metal strain gauges for data acquisition.

\subsection{The Installation of FBGSs and Its Data Acquisition Equipment (DAE)}

This experiment uses the clip-type FBGSs, experimenter machines semicircular metal clip according to the external dimensions of steel strand, then fix the clip-type FBGS the on the steel strand by bolt connection. The installation of FBGSs on the cable is shown in Figure 1.

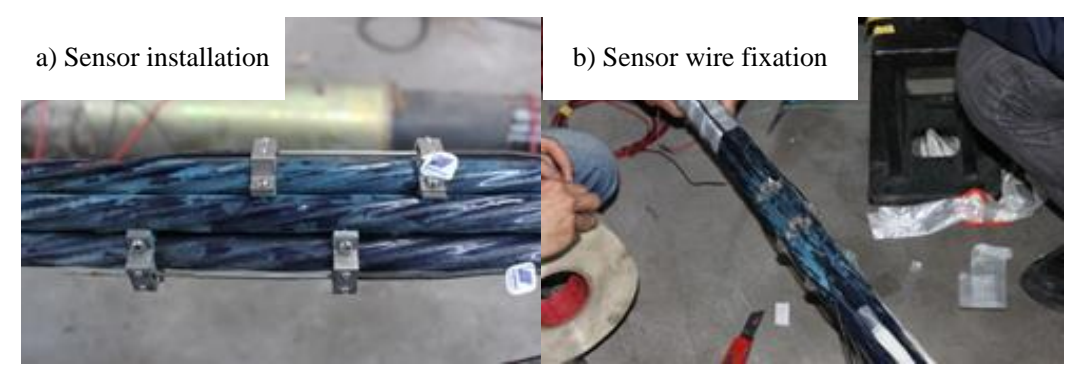

Figure 1. The Installation of FBGSs on the Cable

FBGSs(1\#, 2\#, 3\#, 4\#) are respectively installed on the steel strands numbered by 1-1, 2-1, 2-3,3-1, as shown in Figure 2. The fiber grating sensor interrogating system for date acquisition is shown in Figure 3. 


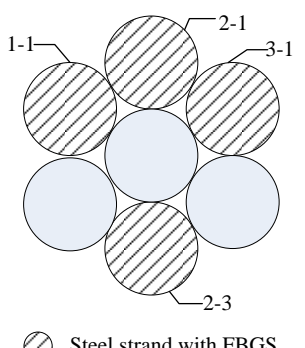

Steel strand with FBGS

\section{Figure 2. FBGS Installation Location}

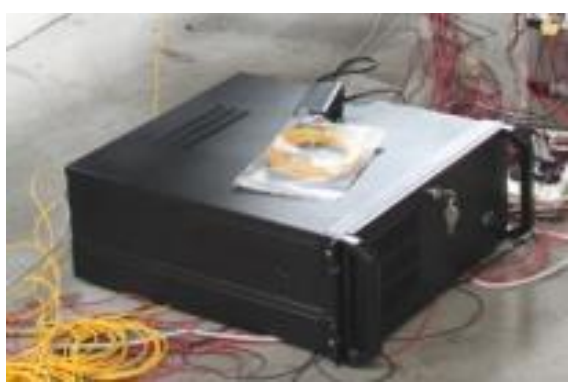

\section{Figure 3. Fiber Grating Sensor Interrogating System}

\subsection{The Installation of Metal Strain Gauges and Its DAE}

Before the installation of metal strain gauges, it needs to grind epoxy-coated steel wire strands by wool felt, which does not destroy the steel strands' structure. Then, clean the surfaces of steel strands with acetone. The processed steel wires are shown in Figure 4.a). Attach metal strain gauges to the surfaces of steel strands with the 502 glue, as shown in Figure 4.b). The method to connect metal strain gauges and wires is welding, as shown in Figure 4.c). This experiment uses 60 channels strain acquisition instrument from DongHua Test Co., Ltd to acquire data, as shown in Figure 4.d).
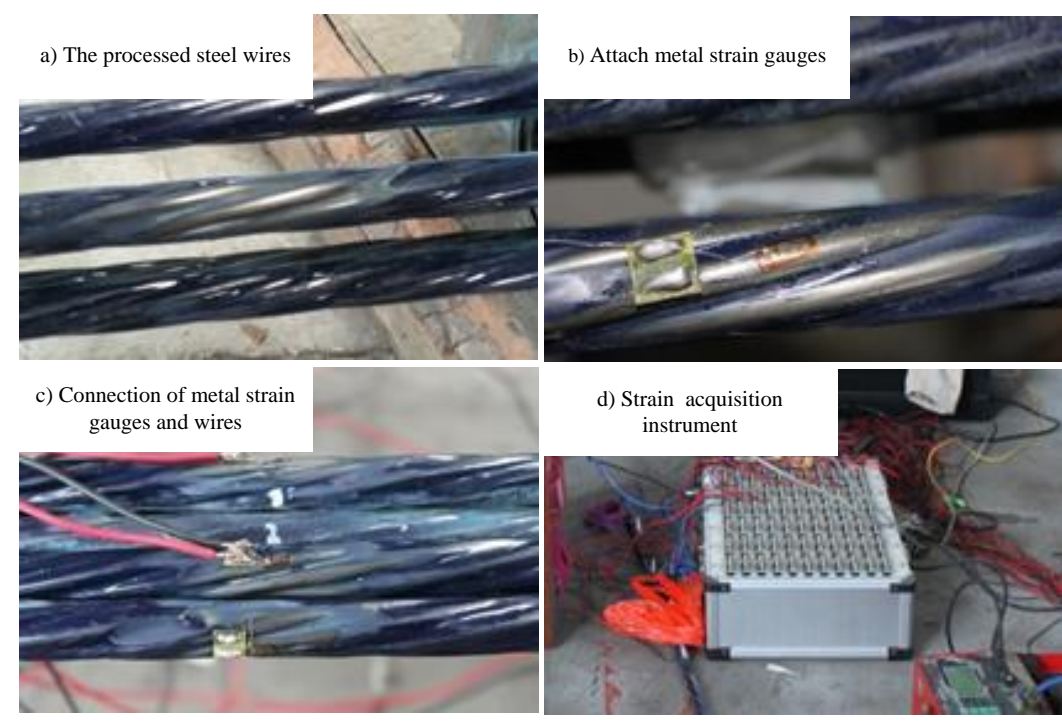

Figure 4. The Installation of Metal Strain Gauges and DAE 


\subsection{The Test Equipment and Installation of the Cable}

The cable broken wires calibration test is done on the funicular machine in Jiangyin FASTEN SUMIDEN New Material Co., Ltd. The test equipment includes funicular machine, oil jack, and pressure sensors. The cables' accessories include anchor plate, supporting hinge etc. The components of funicular machine include a counter force frame, through-type pressure sensor, through -type oil jack, the lifting pulley bracket, cushion blocks. As shown in Figure 5.

The installation process of the cable is as follows: plug the cable into the side equipped with pressure sensors, then pull it out from the side equipped with a through-type oil jack, On the midway the cable successively passes through the cushion blocks, pressure sensor, counter force frame, through-type oil jack, anchor plate, supporting hinge. The cable's installation diagram is shown in Figure 6. Before testing, insure the cable centered, adjust the cushion block's position and the cable's position by the lifting pulley. Before the whole steel strands are tensioned, do the manual tuning by using a sledgehammer. The installation process of oil jack and clamping piece next anchor plate is shown in Figure 7. After the installation, adjust each steel stand to ensure these cables tensioned evenly.

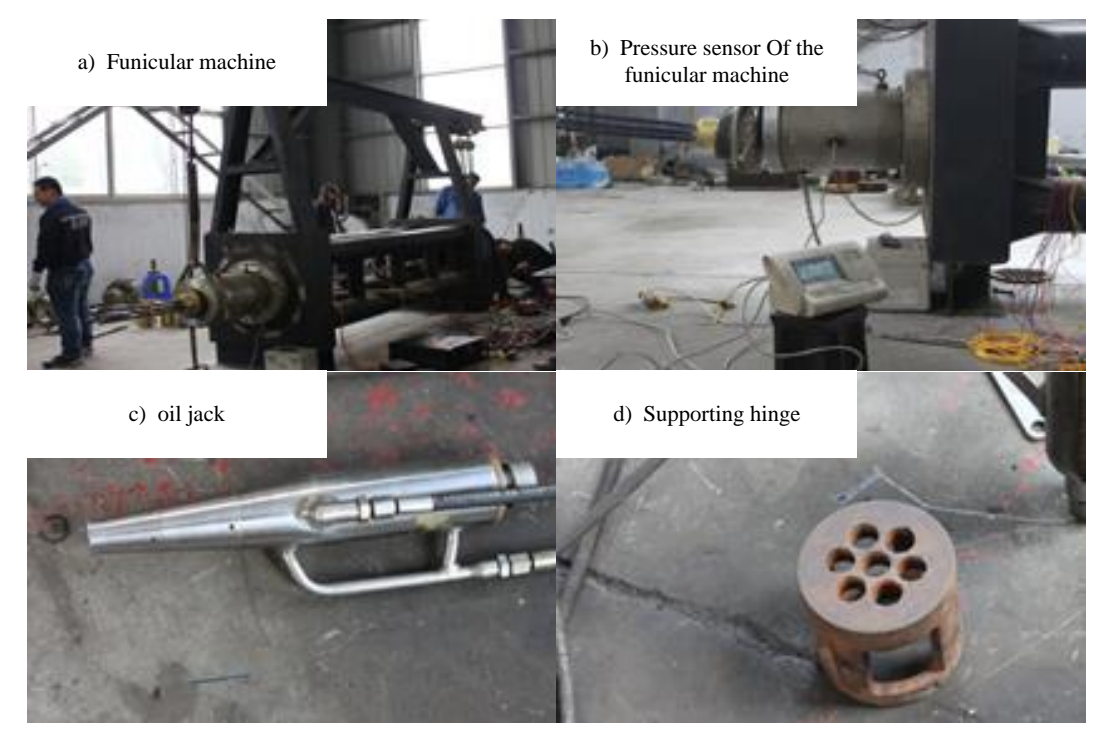

Figure 5. The Test Equipment

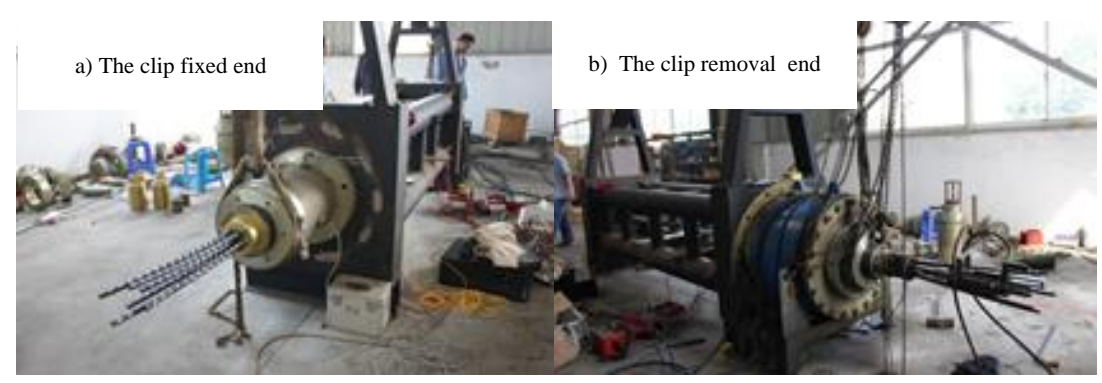

Figure 6. The Cable's Installation Diagram 


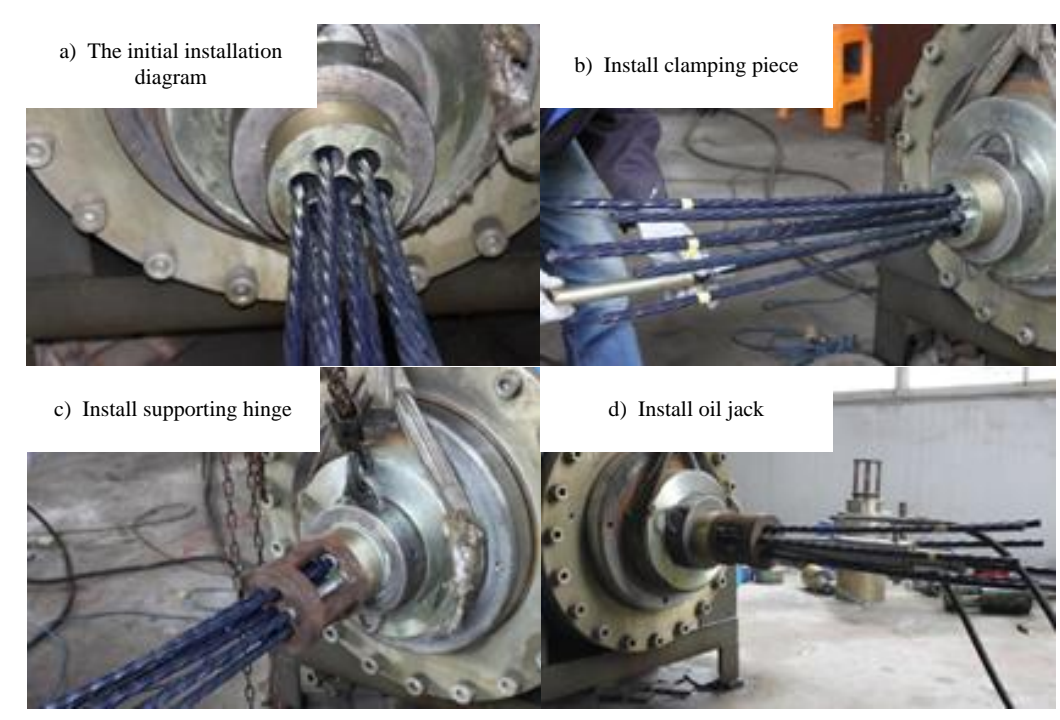

Figure 7. The Installation Process about Oil Jack and Clamping Piece Next Anchor Plate

\subsection{Verify the Work State of FBGSs}

In order to verify that the FBGSs are working properly and check whether the installation is correct, it needs to stretch the cable and analyze the linearity of the FBGSs. First, stretch the cable three times so that the steel strands have the uniform stress, then record the data about the fourth and fifth tension. The sensors and the locations are labeled 1\#, 2\#, 3\#, and 4\# as shown in Figure 2. The sensors' wavelength-load curves about the last two tensions are shown in Figure 8.
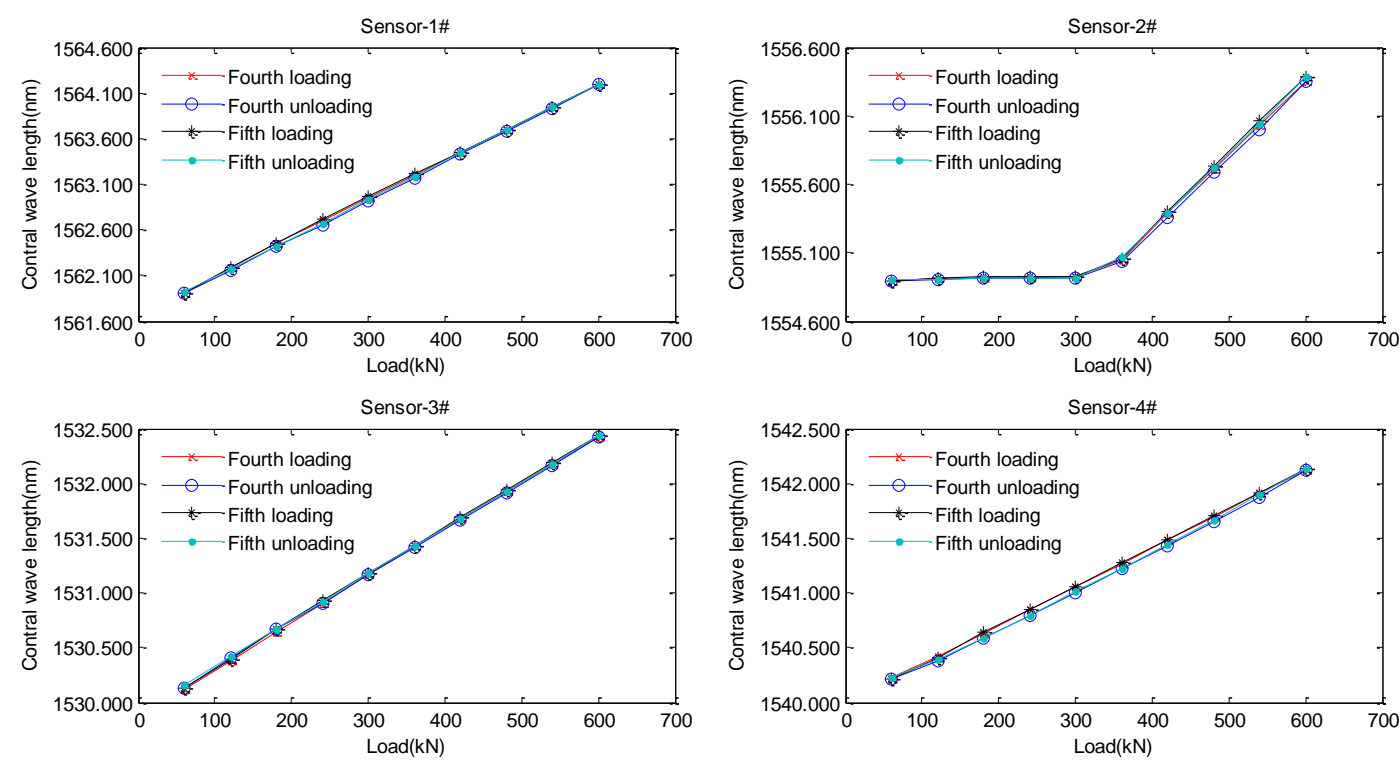

Figure 8. The Sensors Wavelength-load Curves

Through the above graph we can know that $1 \#, 3 \#, 4 \#$ are working properly with good linearity, which effectively reflects the relationship between cable tension and the wavelength change. At the first half of the test, $2 \#$ has no response to the stretch it means 
this sensor stays in a slack condition. Therefore, reinstall the sensor 2\# before the wire break experiment. The strands may stay in the micro-bending state when there is no tension on them, so we can't regard the wavelength as the FBGSs' initial value when the force is zero. Instead, the paper gets the FBGSs' initial wavelength $\lambda 0$ by the calculation. Concrete analysis is as follows.

According to the tension of the whole cable, we can get strain coefficient $\mathrm{K}$, then a single steel strand's strain coefficient $\mathrm{K} 1$ is $\mathrm{K} / 7$. Solve the ${ }^{\lambda 0}$ by the formula $F=K^{*} \Delta \lambda$. The FBGSs' parameters are shown in Table 1.

Table 1. FBGSs' Parameters

\begin{tabular}{lllll}
\hline Parameter & $1 \#$ & 2\# & $3 \#$ & $4 \#$ \\
\hline K1 & 33.857 & 26.143 & 33.429 & 40.143 \\
$\lambda 0$ & 1561.526 & 1554.994 & 1530.374 & 1540.523 \\
\hline
\end{tabular}

\subsection{The Wire Break Monitoring Test Method and Test Condition}

The specific load implementation process is as follows: firstly, assembling steel strand and straightening the cable. Secondly, tension every steel strand under the level 1 , the ring type pressure sensor shows that each strand's force is $6 \mathrm{kN}$. Finally, tension the last steel strand with oil jack, and lock the jack when the force reaches $6 \mathrm{kN}$. After tensioning the whole cable to the predetermined load, take off the oil jack. Three groups test were done repeatedly, the test conditions are shown in Table 2.

Table 2. Test Condition

\begin{tabular}{cccc}
\hline \multirow{2}{*}{ Condition number } & The first group test & The second group test & The third group test \\
\cline { 2 - 4 } & \multicolumn{3}{c}{ The released steel strand number } \\
\hline 1 & $1-2$ & $1-2$ & $1-2$ \\
2 & $2-1$ & $1-1$ & $1-1$ \\
3 & $3-2$ & $3-2$ & $3-2$ \\
4 & $2-2$ & $2-2$ & $2-2$ \\
\hline
\end{tabular}

\section{The Test Results and Data Analysis}

\subsection{Analysis of Metal Strain Gauges' Test Data}

The locations of metal stain gauges are shown in Figure 9 and the anchoring length of the cable is $5 \mathrm{~m}$. Paste positions of metal strain gauges are respectively located at $0.2 \mathrm{~m}$, $1 \mathrm{~m}, 2.2 \mathrm{~m}, 3 \mathrm{~m}$, and $4 \mathrm{~m}$ from the left side. Respectively mark them as point $1,2,3,4,5$. Install metal strain gauges on the point 1, 2, 3, 4 locations on steel strands2-1, 2-2, 31.And install metal strain gauges on the point 5 of the whole 7 steel strands. The position of FBGS is located at $2.0 \mathrm{~m}$ from the left side of the whole steel strands. Through the analysis of experimental data, the calibration curves of strain values and the amount of broken wires about different measuring points are shown in Figure 9.

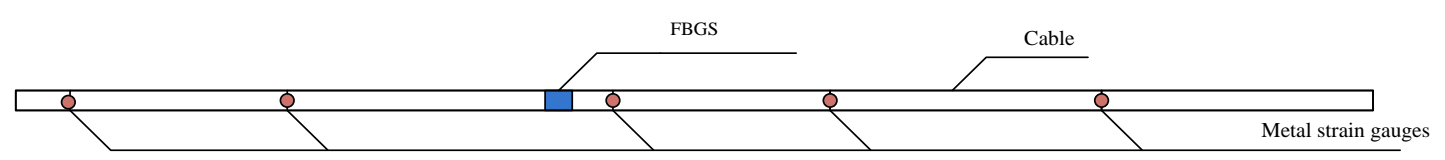

Figure 9. The Locations of Metal Stain Gauges 
As shown in the graph, the change trends of measuring points are consistent. There is a certain deviation among the different points on one steel strand concerned with the strand steels' initial state, as well as the condition that the steel strands in the test is placed horizontally and the process of tensioning is horizontal. In the initial period of straightening, the strain gauges are not the real zero stress states, the initial strain value of each point exists a certain deviation. Through analyzing the experimental date, we can find that the calibration curves of strain value and broken wires tend to uniformity. There is no this kind of deviation in the actual bridge engineering because of the cables of arch bridges and suspension bridges are tensioned vertically. Moreover, the paste of some strain gauges is defectively, there is offset error with the measurement data. When do the analysis and data fitting, it needs to eliminate the data which has offset error. From the data in the figure we can draw the conclusion that strain values increase obviously with the change of the amount of broken wires, and the usage of strain value to calibrate the amount of broken wires is feasible.

The experimental data of the metal strain gauges are shown in Figure 10. The calibration curves' differences about strain values and broken wires among each measuring points on one steel strand are very small. It shows that when one steel strand breaks, the influences of friction on other strands' measuring points are uniform. It is hardly to ensure that the tension forces on each steel strand are identical in the process of tensioning, resulting in the uneven distribution of the forces on each steel strand. In the data fitting analysis we should average experimental data of the whole steel strands, then get the mean values about each group test as shown in Table 3. Using MATLAB for the polynomial curve fitting of experimental data, respectively deal the experimental data with quadratic polynomial, cubic polynomial and quartic polynomial data fitting. The quadratic polynomial, cubic polynomial and quartic polynomial are as follows:

$$
\begin{aligned}
& f_{2}(x)=9642.1 x^{2}+8413 x+2700.9 \\
& \quad f_{3}(x)=10306 x^{3}+809 x^{2}+2650 x+2665 \\
& f_{4}(x)=44240 x^{4}-40255 x^{3}+18481 x^{2}+807 x+2671
\end{aligned}
$$



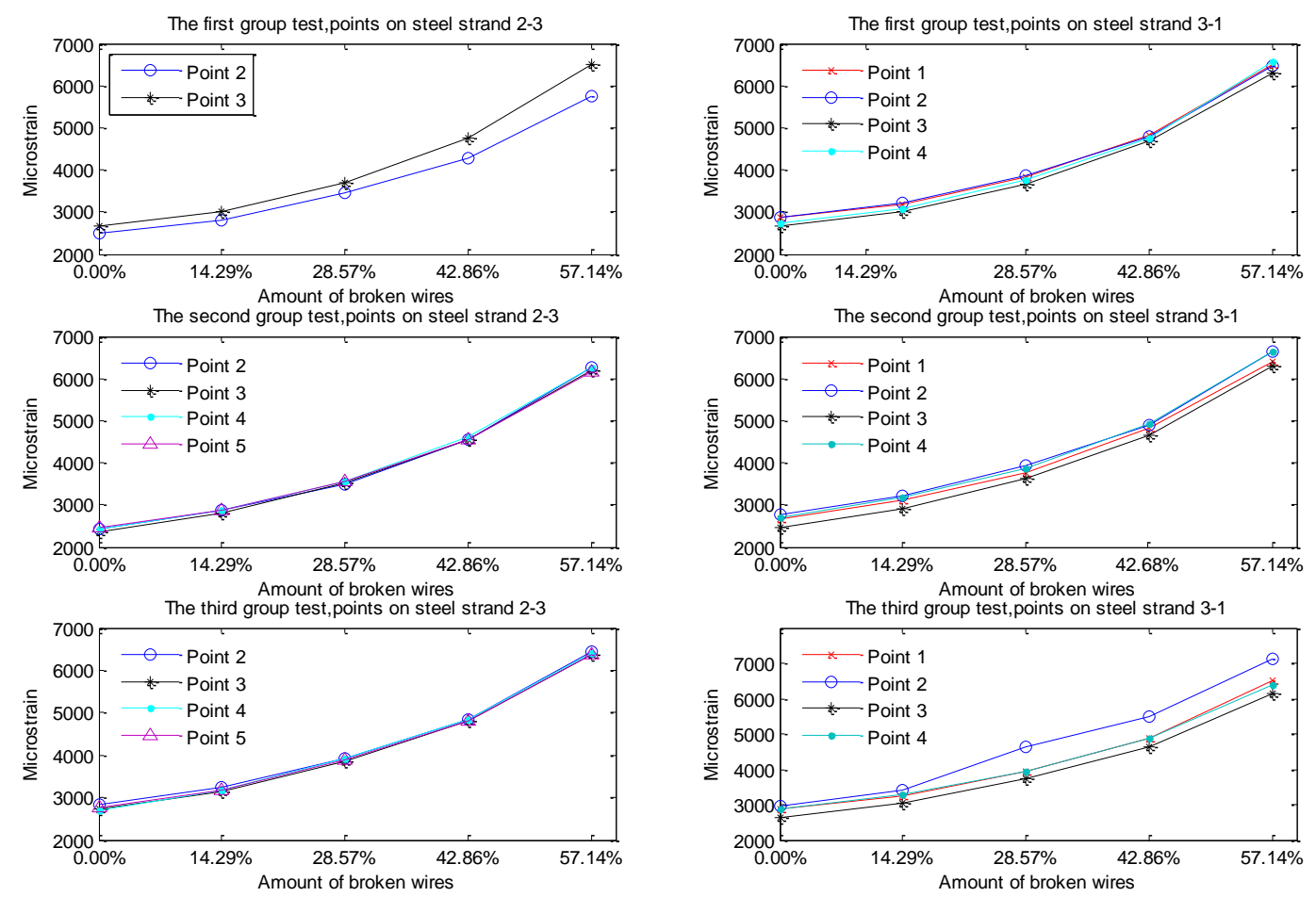

Figure 10. The Calibration Curves of Strain Value and Amount of Broken Wires

The fitted data is shown in Table 3. The fitted curves of experimental data are shown in Figure 11. And the error analysis is shown in Table 4. By means of analyzing the standard deviation and the error value, when using cubic polynomial for data fitting, the precision is higher and the result is reliable. The calibration curve of the polynomial is shown in Figure 12, according to the analysis of the standard deviation of the experimental data, getting the upper and lower bounds of strain calibration curves, we can judge the range of broken wires' quantity corresponding to the strain values. Based on the calibration curve we can estimate the amount of broken wires, thus determining the necessity of cable replacement.

Table 3. The Mean Values of Each Group and the Strain Values of The Fitted Curves

\begin{tabular}{|c|c|c|c|c|c|c|}
\hline \multirow{2}{*}{$\begin{array}{c}\text { Amount of } \\
\text { broken } \\
\text { wires }\end{array}$} & \multirow{2}{*}{$\begin{array}{c}\text { Mean } \\
\text { strains of } \\
\text { group } 1\end{array}$} & \multirow{2}{*}{$\begin{array}{c}\text { Mean } \\
\text { strains of } \\
\text { group } 2\end{array}$} & \multirow[b]{2}{*}{$\begin{array}{c}\text { Mean strain } \\
\text { of group } 3\end{array}$} & \multicolumn{3}{|c|}{ The train values of the fitted curve } \\
\hline & & & & $\begin{array}{l}\text { Quadratic } \\
\text { polynomial }\end{array}$ & $\begin{array}{c}\text { Cubic } \\
\text { polynomial }\end{array}$ & $\begin{array}{l}\text { Quartic } \\
\text { polynomial }\end{array}$ \\
\hline $0.00 \%$ & 2673.5 & 2540.13 & 2799.88 & 2700.9 & 2664.9 & 2671.2 \\
\hline $14.29 \%$ & 2998.38 & 2981.00 & 3215.13 & 3018 & 3090.1 & 3064.8 \\
\hline $28.57 \%$ & 3654.88 & 3665.88 & 3977.75 & 3728.3 & 3728.3 & 3766.2 \\
\hline $42.86 \%$ & 4613.38 & 4692.63 & 4900.00 & 4832.7 & 4760.6 & 4735.3 \\
\hline $57.14 \%$ & 6290.88 & 6357.38 & 6468.13 & 6329.7 & 6365.8 & 6372.1 \\
\hline \multicolumn{4}{|c|}{ Standard deviation } & 142.07 & 135.92 & 139.5834 \\
\hline
\end{tabular}


Table 4. Error Analysis of Polynomial Curve Fitting

\begin{tabular}{lllllllll}
\hline \multicolumn{2}{l}{ Quadratic polynomial } & \multicolumn{3}{c}{ Cubic polynomial } & \multicolumn{3}{c}{ Quartic polynomial } \\
\hline Group 1 & Group 2 & Group 3 & Group 1 & Group 2 & Group 3 & Group 1 & Group 2 & Group 3 \\
\hline $1.01 \%$ & $5.95 \%$ & $-3.66 \%$ & $-0.32 \%$ & $4.68 \%$ & $-5.06 \%$ & $-0.09 \%$ & $4.91 \%$ & $-4.82 \%$ \\
$0.65 \%$ & $1.23 \%$ & $-6.53 \%$ & $2.97 \%$ & $3.53 \%$ & $-4.05 \%$ & $2.17 \%$ & $2.73 \%$ & $-4.91 \%$ \\
$1.97 \%$ & $1.67 \%$ & $-6.69 \%$ & $1.97 \%$ & $1.67 \%$ & $-6.69 \%$ & $2.96 \%$ & $2.66 \%$ & $-5.62 \%$ \\
$4.54 \%$ & $2.90 \%$ & $-1.39 \%$ & $3.09 \%$ & $1.43 \%$ & $-2.93 \%$ & $2.57 \%$ & $0.90 \%$ & $-3.48 \%$ \\
$0.61 \%$ & $-0.44 \%$ & $-2.19 \%$ & $1.18 \%$ & $0.13 \%$ & $-1.61 \%$ & $1.27 \%$ & $0.23 \%$ & $-1.51 \%$ \\
\hline
\end{tabular}

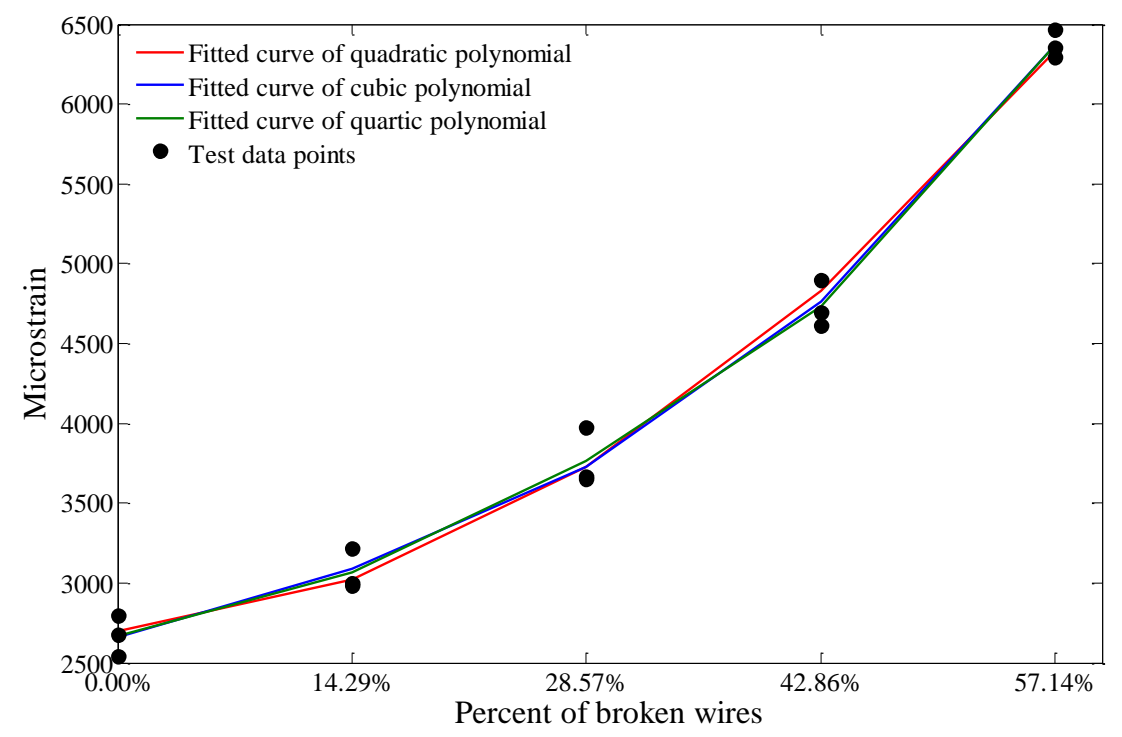

Figure 11. The Fitted Curve of Experimental Data

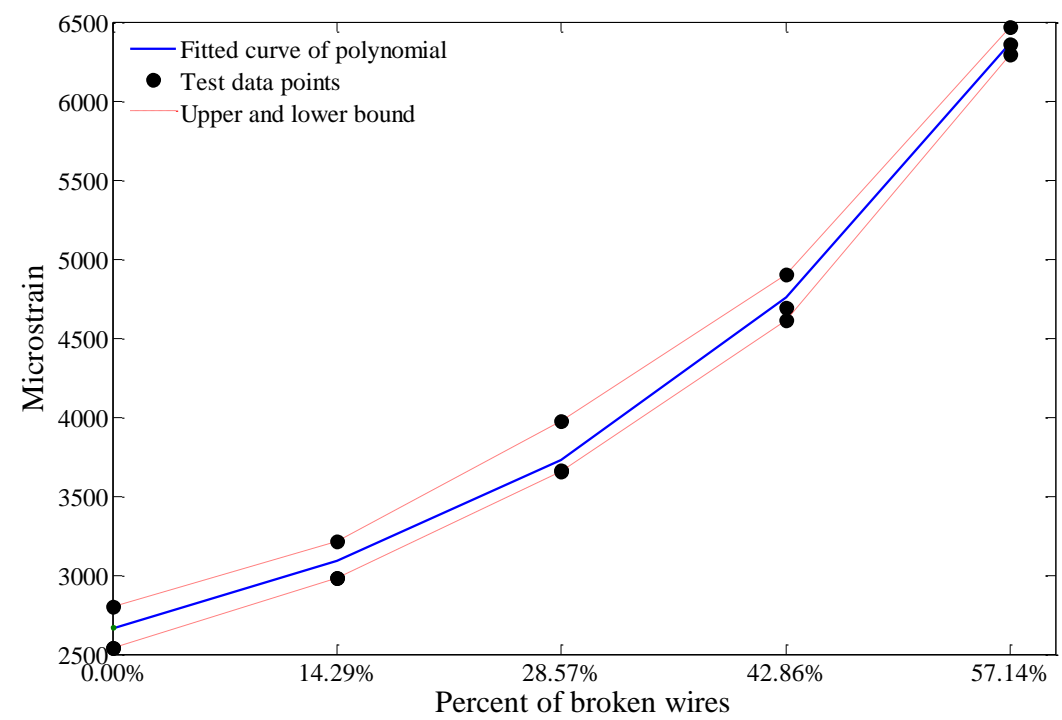

Figure 12. Strain Calibration Curve 


\subsection{Analysis of FBGSs' Test Data}

The test data of FBGSs wavelength corresponding to the amount of broken wires as shown in Table 5 Table 7 The calibration curves of wavelength variation and the amount of broken wires are shown in Figure $13 \sim$ Figure 15.

Table 5. The Wavelength Corresponding to Amount of Broken Wires in the First Group Test

\begin{tabular}{|c|c|c|c|c|c|c|}
\hline \multicolumn{4}{|c|}{ Wavelengths of FBGSs (nm) } & \multirow{2}{*}{$\begin{array}{l}\text { Tension } \\
(\mathrm{kN})\end{array}$} & \multirow{2}{*}{ Amount of broken wires } & \multirow{2}{*}{$\begin{array}{l}\text { Steel } \\
\text { strand }\end{array}$} \\
\hline $1 \#$ & $2 \#$ & $3 \#$ & 4\# & & & \\
\hline 1564.102 & 1556.196 & 1532.845 & 1542.521 & 554 & $0.00 \%$ & \\
\hline 1564.880 & 1556.523 & 1533.155 & 1542.723 & 554 & $14.29 \%$ & $1-2$ \\
\hline 1565.449 & 1558.653 & 1533.595 & 1540.402 & 554 & $28.57 \%$ & $2-1$ \\
\hline 1566.381 & 1563.946 & 1533.780 & 1540.258 & 553 & $42.86 \%$ & $3-2$ \\
\hline 1567.950 & 1565.399 & 1535.063 & 1540.353 & 553 & $57.14 \%$ & $2-2$ \\
\hline
\end{tabular}

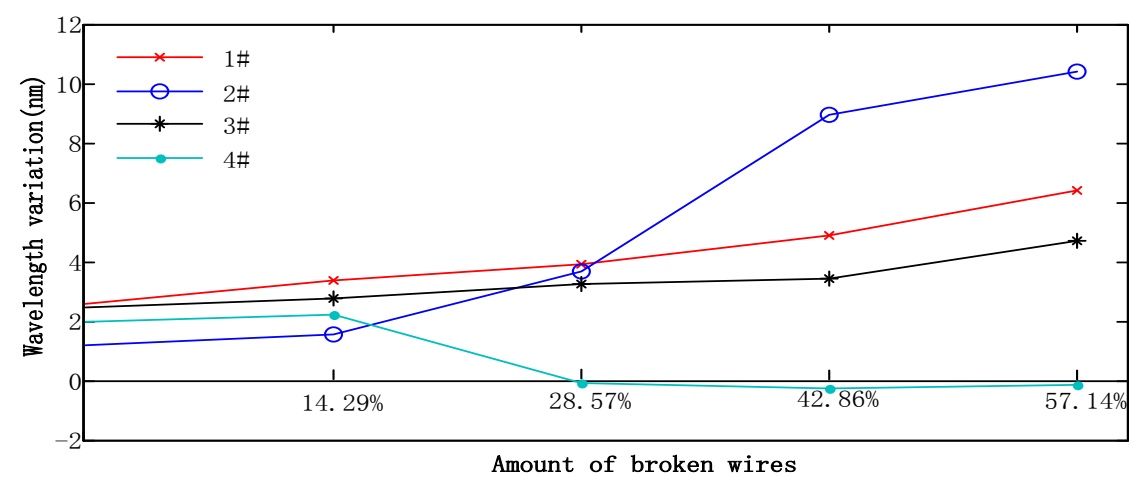

Figure 13. The Calibration Curves of Wavelength Variation and Amount of Broken Wires in the First Group Test

Table 6. The Wavelength Corresponding to Amount of Broken Wires in Second Group Test

\begin{tabular}{cccccccc}
\hline \multicolumn{4}{c}{ Wavelengths of FBGSs $(\mathrm{nm})$} & & $\begin{array}{l}\text { Tension } \\
(\mathrm{kN})\end{array}$ & Amount of broken wires & $\begin{array}{c}\text { Steel } \\
\text { strand }\end{array}$ \\
\hline 1 1\# & $2 \#$ & $3 \#$ & 4\# & & $0.00 \%$ & \\
1561.718 & 1557.582 & 1533.210 & 1541.775 & 554 & $14.29 \%$ & $1-2$ \\
1562.050 & 1557.891 & 1533.637 & 1542.021 & 554 & $28.57 \%$ & $1-1$ \\
1559.988 & 1558.295 & 1534.243 & 1542.581 & 555 & $42.86 \%$ & $3-2$ \\
1559.989 & 1559.248 & 1534.731 & 1543.275 & 554 & $57.14 \%$ & $2-2$ \\
1559.988 & 1561.184 & 1536.101 & 1544.518 & 555 & & \\
\hline
\end{tabular}




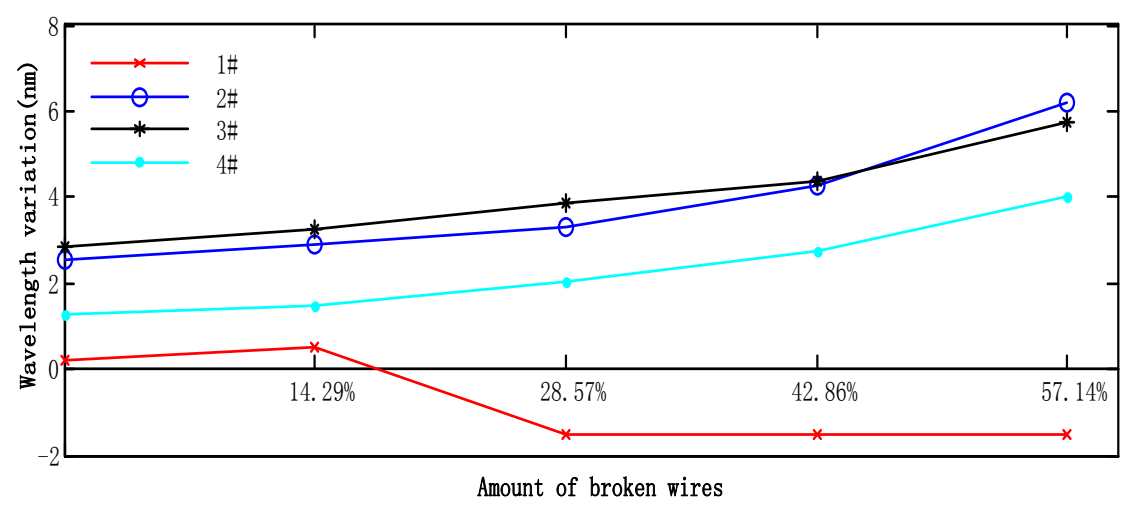

Figure 14. The Calibration Curves of Wavelength Variation and Amount of Broken Wires in the Second Group Test

Table 7. The Wavelength Corresponding to Amount of Broken Wires in the Third Group Test

\begin{tabular}{|c|c|c|c|c|c|c|}
\hline \multicolumn{4}{|c|}{ Wavelengths of FBGSs (nm) } & \multirow{2}{*}{ Tension $(\mathrm{kN})$} & \multirow{2}{*}{ Amount of broken wires } & \multirow{2}{*}{$\begin{array}{l}\text { Steel strand } \\
\text { be released }\end{array}$} \\
\hline $1 \#$ & 2\# & 3\# & 4\# & & & \\
\hline 1561.444 & 1556.019 & 1533.316 & 1542.110 & 553 & $0.00 \%$ & \\
\hline 1561.753 & 1556.392 & 1533.683 & 1542.365 & 552 & $14.29 \%$ & $1-2$ \\
\hline 1559.991 & 1556.947 & 1534.196 & 1542.792 & 554 & $28.57 \%$ & $1-1$ \\
\hline 1559.988 & 1557.197 & 1534.561 & 1543.478 & 555 & $42.86 \%$ & $3-2$ \\
\hline 1559.988 & 1558.992 & 1535.714 & 1544.541 & 554 & $57.14 \%$ & $2-2$ \\
\hline
\end{tabular}

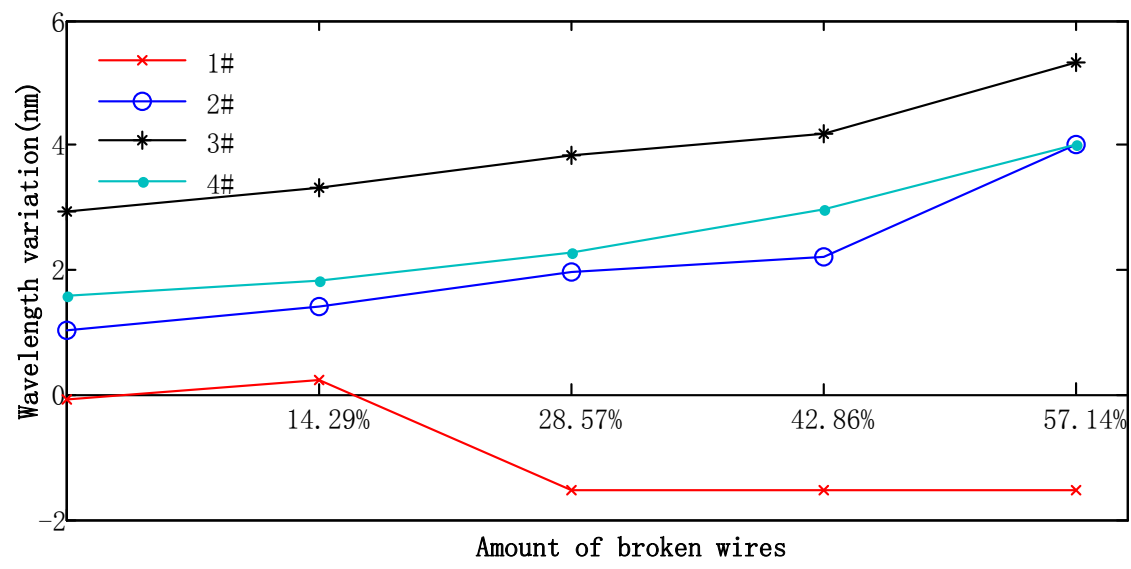

\section{Figure 15. The Calibration Curves of Wavelength Variation and Amount of Broken Wires in the Second Group Test}

After broken wires' amount reaches $14.29 \%$, the sensor $4 \#$ in the first group test is no more under tension, because the corresponding steel strand is released in second condition. The same is true with sensor $1 \#$ in the second and third group. What's more, some block rake caused by the adjacent steel strand appears in the sensor $2 \#$ in the first group of the test, and it leads to greater data changes. So, reinstall the sensor $2 \#$ in the following test. Other FBGSs' wavelength increases with the decrease of steel strands' quantity, conforming to regularity.

The experimental data of the FBGSs is collected, since the steel strand with sensor1 \# was released during the process of the simulation, the wavelength increment is 0 after broken wires amount reaches $14.29 \%$; sensor $2 \#$ occurred slip at the early stage of the 
simulation, the test data also has some deviations after the adjustment. During the next analysis, subject to the test data of sensor 3\# and sensor 4\#. The mean values of sensor 3\# or sensor 4\# in each group test are shown in Table 8. Using MATLAB for the polynomial curve fitting of experimental data, respectively deal the experimental data with quadratic polynomial, cubic polynomial and quartic polynomial data fitting. The quadratic polynomial, cubic polynomial and quartic polynomial are as follows:

$$
\begin{aligned}
& f_{2}(x)=6.2930 x^{2}+0.8251 x+2.1879 \\
& f_{3}(x)=12.7750 x^{3}-4.6560 x^{2}+3.0668 x+2.1432 \\
& f_{4}(x)=79.0714 x^{4}-77.5946 x^{3}+26.929 x^{2}-0.2271 x+2.1545
\end{aligned}
$$

\begin{tabular}{|c|c|c|c|c|c|}
\hline \multirow{2}{*}{$\begin{array}{c}\text { Amount of } \\
\text { broken wires }\end{array}$} & \multirow{2}{*}{$\begin{array}{c}\text { Mean strains } \\
\text { of group } 2\end{array}$} & \multirow{2}{*}{$\begin{array}{c}\text { Mean strains } \\
\text { of group } 3\end{array}$} & \multicolumn{3}{|c|}{ The change of wavelength about fitted curves } \\
\hline & & & $\begin{array}{l}\text { Quadratic } \\
\text { polynomial }\end{array}$ & $\begin{array}{c}\text { Cubic } \\
\text { polynomial }\end{array}$ & $\begin{array}{r}\text { Quartic } \\
\text { polynomial }\end{array}$ \\
\hline $0.00 \%$ & 2.044 & 2.265 & 2.1879 & 2.1432 & 2.1545 \\
\hline $14.29 \%$ & 2.381 & 2.576 & 2.4343 & 2.5237 & 2.4785 \\
\hline $28.57 \%$ & 2.964 & 3.046 & 2.9373 & 2.9373 & 3.0050 \\
\hline $42.86 \%$ & 3.555 & 3.571 & 3.6975 & 3.6082 & 3.5630 \\
\hline $57.14 \%$ & 4.861 & 4.679 & 4.7140 & 4.7587 & 4.7700 \\
\hline \multicolumn{3}{|c|}{ Standard deviation } & 0.1316 & 0.1164 & 0.1127 \\
\hline
\end{tabular}

\section{Table 8. The Mean Strains of Each Group and the Change of Wavelength about Fitted Curves}

The fitted data is shown in Table 8. The fitted curves of experimental data are shown in Figure 16. And the error analysis is shown in Table 9. By means of analyzing the standard deviation and the error value, when using cubic polynomial for data fitting the precision is higher and the result is reliable. The calibration curve of the polynomial is shown in Figure 17, according to the analysis of the standard deviation of the experimental data, getting the upper and lower bounds of strain calibration curves, and we can judge the range of broken wires' quantity corresponding to the change of wavelength. Based on the calibration curve, we can estimate the quantity of broken wires, thus determining the necessity of cable replacement.

Table 9. Error Analysis of Polynomial Curve Fitting

\begin{tabular}{cccccc}
\hline \multicolumn{2}{c}{ Quadratic polynomial } & \multicolumn{2}{c}{ Cubic polynomial } & \multicolumn{2}{c}{ Quartic polynomial } \\
\hline Group 2 & Group 3 & Group 2 & Group 3 & Group 2 & Group 3 \\
\hline $6.58 \%$ & $-3.52 \%$ & $4.63 \%$ & $-5.68 \%$ & $5.13 \%$ & $-5.13 \%$ \\
$2.19 \%$ & $-5.82 \%$ & $5.65 \%$ & $-2.07 \%$ & $3.93 \%$ & $-3.93 \%$ \\
$-0.91 \%$ & $-3.70 \%$ & $-0.91 \%$ & $-3.70 \%$ & $1.36 \%$ & $-1.36 \%$ \\
$3.85 \%$ & $3.42 \%$ & $1.47 \%$ & $1.03 \%$ & $0.22 \%$ & $-0.22 \%$ \\
$-3.12 \%$ & $0.74 \%$ & $-2.15 \%$ & $1.67 \%$ & $-1.91 \%$ & $1.91 \%$ \\
\hline
\end{tabular}




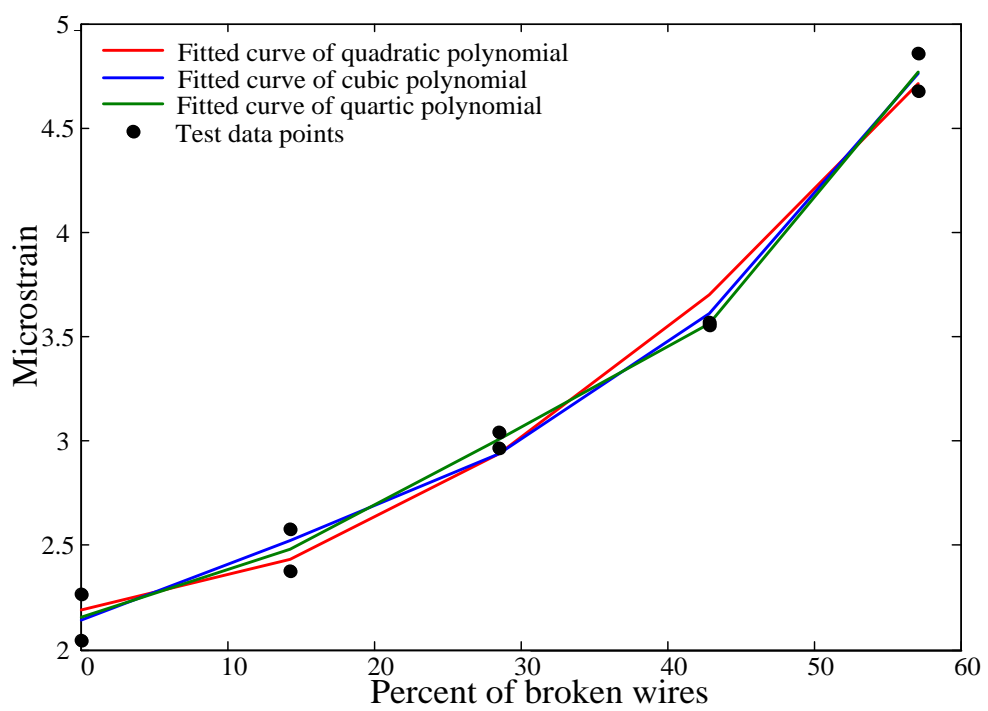

Figure 16. The Fitted Curve of Experimental Data

By analyzing the data of metal strain gauges and FBGSs in this calibration test about cable broken wires, we can find that the shapes of the strain calibration curves are basically the same, which demonstrates that the experimental data is reliable. Because the tension on each steel strand is not uniform so there is some deviation between the increment of wavelength and force, but we can set the scaled boundary through the experiment and then judge the amount of broken wires.

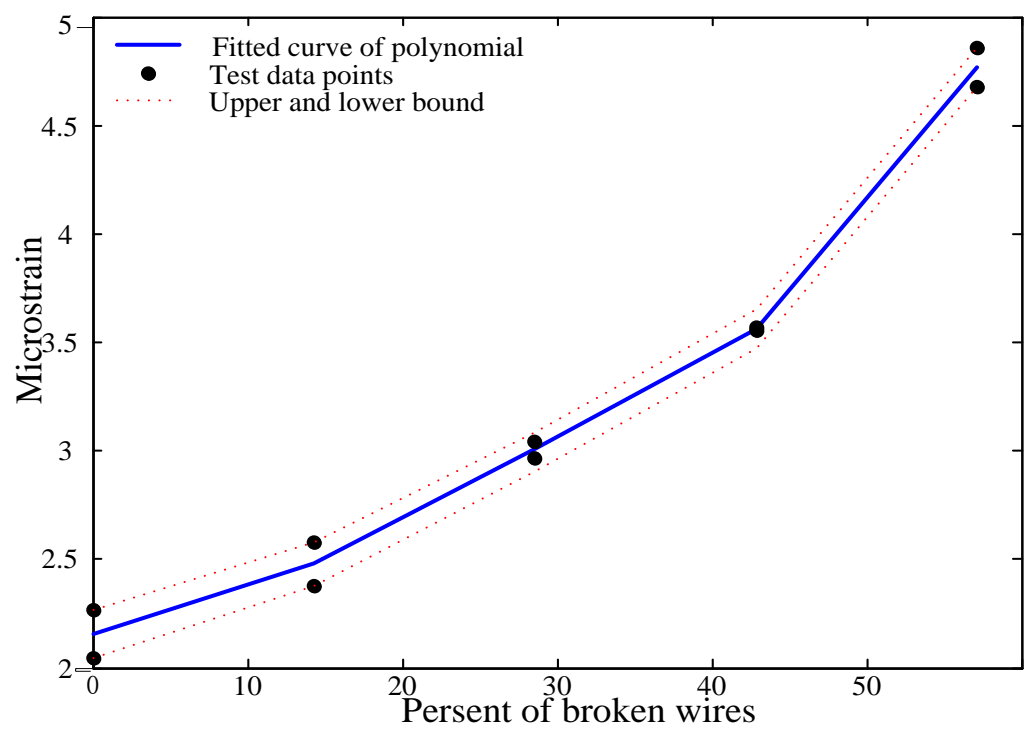

Figure 17. Strain Calibration Curve

\section{Conclusions}

This paper main study on the calibration method of wire breaks in cables. Based on the experiment, taking the theory and method in the application statistics as a foundation, we analyze the experimental date. The results show that the study of this paper provides a reliable basis for judging the amount of broken wires in bridge cables. In practical engineering, for the flexible cable bridges such as arch bridges and suspension bridges, only a few of them load that undertake by this cable will transfer to the adjacent lifting points, due to the stiffness of the bridge deck is smaller when the steel strands of cable 
occur broken wires. In which can be considered as that the cable force remains unchanged during this steel strand breaking process. In this case, the strain calibration curves in this paper can be used as the judging criterion of the broken wire condition.

\section{Author Contribution}

Q.L. and G.L. contributed equally and share the first authorship. Corresponding authors are G.L. and R.J.

\section{Acknowledgements}

This research was supported in part by Research Project of Guangdong Provincial Communication Department (Project No. 2014-02-014). Additional support was provided by a grant from Weihai Science and Technology Development Plan. The authors also would like to thank Dr. Fang Yu for her help and valuable suggestion.

\section{References}

[1] J. M. Ko and Y. Q. Ni, "Technology Developments in Structural Health Monitoring of Large-scale Bridges", Eng. Struct., vol. 27, no. 12, (2005), pp. 1715-1725.

[2] Y. Q. Ni, X. W. Ye and J. M. Ko, "Modeling of Stress Spectrum Using Long-term Monitoring Data and Finite Mixture Distributions", J. Eng. Mech., vol. 138, no. 2, (2011), pp. 175-183.

[3] H. Tabatabai, "Maintenance and Inspection of Bridge Stay Cable System"s, Proceedings of Workshop on Wind-induced Vibration, St. Louis, Missouri, (2006).

[4] H. Li, J. Ou and Z. Zhou, "Applications of Optical Fibre Bragg Gratings Sensing Technology-based Smart Stay Cables", Opt Lasers Eng, vol. 47, no. 10, (2009), pp. 1077-1084.

[5] H. N. Li, D. S. Li and G. B. Song, "Recent Applications of Fiber Optic Sensors to Health Monitoring in Civil Engineering," Eng. Struct., vol. 26, no. 11, (2004), pp. 1647-1657.

[6] P. A. Vanniamparambil, F. Khan, K. Hazeli, J. Cuadra, E. Schwartz, A. Kontsos and I. Bartoli, "Novel Optico - acoustic Nondestructive Testing for Wire Break Detection in Cables", J. Struct. Control Health Monit., vol. 20, no. 11, (2013), pp. 1339-1350.

[7] I. Bartoli, R. Phillips, F. L. di Scalea, S. Salamone, S. Coccia and C. S. Sikorsky, "Load Monitoring in Multiwire Strands by Interwire Ultrasonic Measurements", Proceedings of the Sensors and Smart Structures Technologies for Civil, Mechanical, and Aerospace Systems, The International Society for Optical Engineering, San Diego, CA, United states, (2008).

[8] P. Rizzo and F. L. Di Scalea, "Load Measurement and Health Monitoring in Cable Stays via Guided Wave Magnetostrictive Ultrasonics", Mater Eval, vol. 62, no.10, (2004), pp. 1057-1065.

[9] B. M. Wu, , J. D. Zhang, J. D. Zhang, C. M. Zhu, X. J. Wu and J. Xu, "Effect of Tensile Load for Detecting Broken Wires of Parallel Wire Cable Based on Guided Waves", Applied Mechanics and Materials, vol. 325-326, (2013), pp. 848-851.

[10] W. X. Ren and X. L. Peng, "Baseline Finite Element Modeling of a Large Span Cable-stayed Bridge through Field Ambient Vibration Tests", Comput Struct, vol. 83, no. 8, (2005), pp. 536-550.

[11] W. X. Ren, , Y. Q., Lin, and X. L., Peng, "Field Load Tests and Numerical Analysis of Qingzhou CableStayed Bridge", J Bridge Eng, vol. 12, no. 2, (2007), pp. 261-270.

[12] J. M. Brownjohn, J. Lee and B. Cheong, "Dynamic Performance of a Curved Cable-stayed Bridge", Eng Struct, vol. 21, no. 11, (1999), pp. 1015-1027.

[13] S. C., Liu, D. S. Jiang and S. Li, "Application of Optic Fiber Grating Vibration Sensor to Cable Tension Measuring of Cable-stayed Bridges", Journal of Wuhan University of Technology, vol. 28, no. 8, (2006), pp. $110-121$

[14] A. B. Mehrabi, C. A. Ligozio, A. T. Ciolko and S. T. Wyatt, "Evaluation, Rehabilitation Planning, and Stay-Cable Replacement Design for the Hale Boggs Bridge in Luling, Louisiana”, J Bridge Eng, vol. 15, no. 4, (2010), pp. 364-372.

[15] J. He, Z. Zhou and O. Jinping, "Optic Fiber Sensor-based Smart Bridge Cable with Functionality of Self-sensing”, Mech Syst Signal Process, vol. 35, no. 1, (2013), pp. 84-94. 


\section{Authors}

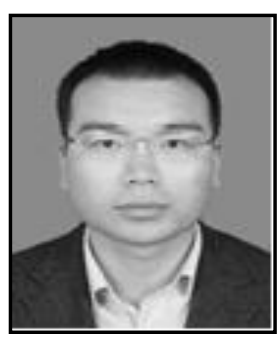

Qiang Liu, he received his B.E. degree in Communication Engineering from North China Institute of Aerospace Engineering, China in 2012. Now he is studying toward the M.S. degree in electronic and communication engineering at Shandong University. His current research interests focus on the health monitoring of the bridge.

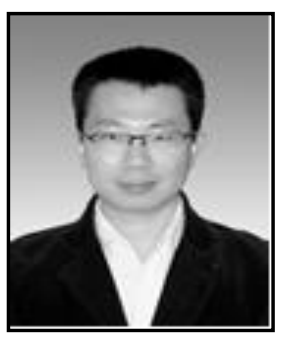

Guangming $\mathbf{L i}$, he received his B.S. degree from Shandong University, China, in 1996, his M.S. degree from the State Key Laboratory of Crystal Materials, Shandong University, in 1999, and his Ph.D. degree from the University of Hong Kong, Hong Kong, in 2006. Now he is an associate professor and supervisor of the Master in Shandong University, Weihai, China. His research interest includes optical networks and internet of things.

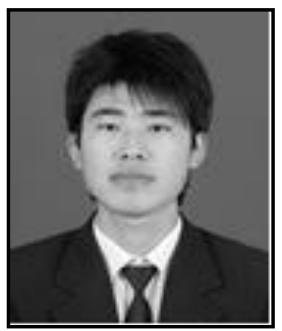

Qingchao Gong, he received his B.E. degree in electronic and information engineering from Harbin Institute of Technology, China in 2013. Now he is studying toward the M.S. degree in electronic and communication engineering at Shandong University. His current research interests focus on wireless sensor networks. 
International Journal of Hybrid Information Technology

Vol. 10, No.2 (2017) 